\title{
Weibull's Analysis of the Dependability of Critical Components of Selected Ag- ricultural Machinery
}

David Fabiánek (0000-0002-7946-6772), Václav Legát (0000-0001-7070-1388), Zdeněk Aleš (0000-0002-25171215)

Faculty of Engineering, Czech University of Life Sciences Prague, Department for Quality and Dependability of Machines, Kamýcká 129, 16521 Prague 6 - Suchdol, Czech Republic, E-mail: fabianekd@tf.czu.cz, legat@tf.czu.cz, ales@tf.czu.cz,

The aim of this paper is an analysis of the dependability of critical components of the John Deer 7530 tractor. For this analysis data was used from a database which contains maintenance data of 166 tractors during approx 9 years. The first part of this article is devoted to the selection of critical components based on number of failures of individual machine parts for a given period and their sales prices. The next part of article presents data for calculation dependability indicators which contains operating times to failure and operating times without failure. Due to the large size of the data files of the individual components, the data are only given for one machine component. Furthermore, the method of calculation of dependability indicators is described by parametric statistical methods according to ČSN EN 61649:2009 and mean time to operating failure. The results of the analysis are summarized in tables and graphs. The method in this article can be used to optimise the maintenance program.

Keywords: Dependability, Weibull distribution, Agriculture, Tractor

\section{Introduction}

At present, manufacturing companies face great pressure from a highly competitive environment and are forced to search new ways to improve production of quality and reduce production costs $[1,2]$. In a constant effort to make the production processes more effective, which aims to achieve a higher level of prosperity and competitiveness of the company, the importance of care for tangible assets is growing, especially the importance of reliability of production equipment (further just "PE"). Great emphasis is placed on keeping PE in high readiness, which generates demanding requirements for their maintenance. By a suitable setting of the maintenance policy, it is possible to significantly extend the operation time until failure, maintenance costs and the life cycle of the PE [3-6]. Many maintenance strategies, policies and methods have been developed, which are aimed at making maintenance cheaper and more effective. Such programs have the minimization of costs, downtime and losses due to failure of critical objects of the equipment as their main objective. Cost minimization improves the effectiveness and profitability of the organization [712].

Significant help in building optimal maintenance programs is the knowledge of dependability indicators. Dependability indicators are:

- Density function of operating time to failure $f(t)$.
- Probability of failure $F(t)$.

- Reliability function $R(t)$.

- Failure rate $\lambda(t)$. $[4,13]$

Many authors research the possibilities of optimizing maintenance in different industries. For example train transport [14, 21], warranty policy [15], machining tools [16], or energetics [17]. Therefore, this paper focuses on obtaining indicators of dependability of PE. Therefore, this article focuses on obtaining indicators of dependability in the industry where maintenance managers neglect using indicators of dependability. This paper demonstrates on 10 critical components of a John Deere 7530 tractor the dependability quantification results obtained using the parameters of the Weibull distribution function which can be an important element in optimizing the tractor maintenance program.

\section{Materials and methods}

For calculate indicators of dependability a database from STROM Praha a.s. was used. The company is exclusive distributor of JOHN DEERE technology for $\mathrm{CZ}$ and also an authorized service. The time period in which the maintenance data were acquired is from 4.1.2010 to 28.5.2019. The number of records is 3262 . Data were recorded for 166 machines. The operating hour $[\mathrm{EH}]$ is used as a unit of operating time. The maintenance record with the smallest wear and tear that appears in the database is $0 \mathrm{EH}$ (probably a pre-sale 
preparation of the machine) and the largest $19006 \mathrm{EH}$.

Critical components of PE were selected by this procedure:

1. Determining the number of occurrences of failures of individual components in the monitored period.

2. Deletion of irrelevant records (objects changed within preventive maintenance programs, work operations, connection of diagnostic devices, etc.).

3. To ensure the usability of the calculated dependability indicators, objects with the number of occurrences of failures $<10$ were removed from the database.

4. The calculate of average prices of components in the monitored period.

5. The criticality was quantified using the equation:

$$
K=n_{F} \cdot C
$$

Where:

K......criticaly

$\mathrm{n}_{\mathrm{F}} \ldots . .$. number of failures in a given time period [1]

C...... average prices of the components for the period [EUR/ given time]

6. Division of components into three categories according to their criticality using Pareto analysis in the ratio $\mathrm{A}=80 \%, \mathrm{~B}=10 \%$ and $\mathrm{C}=10 \%$ of the total cumulative value of the criterion.

7. Selected objects for further research are listed in Tab.1.

It should be added that when selecting objects for further research, emphasis was placed not only on their cost criticality, but also on operational criticality. This means that only such objects were selected which, due to their failure, make it impossible to perform the required production tasks. This fact significantly contributes to the total maintenance costs due to the associated cost items, which in the case of a tractor can be, for example, its towing, repair in difficult conditions (accident site), higher purchase price due to express delivery time, or production losses resulting from non-compliance with agrotechnical deadlines. The input data for the calculation of the dependability indicators of individual objects are in Table Tab. 2. The table contains operating times until the failure of the object and times without failure, socalled incomplete observations (operating time without failure). Only the data for object RE535729 is given in the article as an example due to the large size of the files.
Tab. 1 Selected components for research according to criticality

\begin{tabular}{|c|c|c|}
\hline $\begin{array}{l}\text { Nomencla- } \\
\text { ture of com- } \\
\text { ponents }\end{array}$ & $\begin{array}{l}\text { Name of the no- } \\
\text { menclature }\end{array}$ & $\begin{array}{l}\text { Critica- } \\
\text { lity }\end{array}$ \\
\hline \multirow{3}{*}{ RE535729 } & & 1813695.8 \\
\hline & Exhaust gas cooler & 3 \\
\hline & & 1543399.1 \\
\hline SE502330 & Turbocharger & 8 \\
\hline RE537578 & $\begin{array}{c}\text { Torsional vibration } \\
\text { damper }\end{array}$ & 449349.35 \\
\hline RE43738 & Tensile force sensor & 352457.50 \\
\hline SE501227 & Water pump & 319146.07 \\
\hline AL160250 & Three-way brake valve & 304104.34 \\
\hline AL168483 & Fuel pump & 69313.17 \\
\hline RE543308 & ERG valve & 2510.23 \\
\hline RE523318 & 1 unos artuat & 2453.77 \\
\hline RE167207 & $\begin{array}{c}\text { Engine oil pres } \\
\text { sensor }\end{array}$ & 416.62 \\
\hline
\end{tabular}

The data were processed using the Weibull analysis with the support of an Excel spreadsheet. The analysis procedure was in accordance with the standard CSN EN 61649:2009 [18]:

1. Ascending order of input data

2. Bernard's approximation

3. Replacement of a modified distribution function $F(t)$

4. Linear regression - linear equation

a) Calculation of parameter $a$ of shape and $\beta$ scale of Weibull distribution [19, 20]

Furthermore, other dependability indicators were calculated.

1. The Weibull distribution probability density function of operating time to failure

$$
f(t)=\frac{\alpha_{t}}{\beta_{t}^{\alpha}} \cdot t^{\alpha_{t}-1} \cdot \exp \left[-\left(\frac{t}{\beta_{t}}\right)^{\alpha_{t}}\right]
$$

Where:

$a_{t} \ldots$ Shape parameter of Weibull distribution [-],

$\beta_{t}$...Scale parameter of Weibull distribution [-],

$t$... Operating time to failure $[\mathrm{EH}]$.

2. Reliability function $R(t)$

$$
\boldsymbol{R}(\boldsymbol{t})=\exp \left[\left[-\left(\frac{t}{\beta_{t}}\right)^{\alpha_{t}}\right]\right]
$$

3. Probability of failure $F(t)$

$$
F(t)=1-\exp \left[\left[-\left(\frac{t}{\beta_{t}}\right)^{\alpha_{t}}\right]\right]
$$

4. Failure rate $\lambda(t)$

$$
\lambda(t)=\frac{\alpha_{t}}{\beta_{t}} \cdot\left(\frac{t}{\beta_{t}}\right)^{\alpha_{t}-1}=\frac{f(t)}{R(t)}
$$

Mean Operating Time to Failure $E(t)=M O T T F$

$$
\text { MOTTF }=\beta \cdot \Gamma\left(1+\frac{1}{\alpha}\right)
$$


Tab. 2 Input data for calculation of object dependability indicators RE535729 Flue gas return cooler

\begin{tabular}{|c|c|c|c|c|c|c|c|c|c|c|c|}
\hline \multicolumn{12}{|c|}{ Failure number } \\
\hline \multicolumn{12}{|c|}{ Operating time to failure $[\mathrm{EH}]$} \\
\hline 1 & 2 & 3 & 4 & 5 & 6 & 7 & 8 & 9 & 10 & 11 & 12 \\
\hline 2 & 1080 & 1303 & 1820 & 1913 & 2057 & 2200 & 2205 & 2311 & 2377 & 2642 & 2798 \\
\hline 13 & 14 & 15 & 16 & 17 & 18 & 19 & 20 & 21 & 22 & 23 & 24 \\
\hline 2906 & 2912 & 2965 & 2997 & 3053 & 3271 & 3296 & 3470 & 3532 & 3602 & 3671 & 3727 \\
\hline 25 & 26 & 27 & 28 & 29 & 30 & 31 & 32 & 33 & 34 & 35 & 36 \\
\hline 3762 & 3792 & 3917 & 3948 & 4057 & 4148 & 4183 & 4401 & 4452 & 4471 & 4578 & 4752 \\
\hline 37 & 38 & 39 & 40 & 41 & 42 & 43 & 44 & 45 & 46 & 47 & 48 \\
\hline 4904 & 4982 & 5001 & 5117 & 5150 & 5194 & 5417 & 5523 & 5770 & 5790 & 5814 & 5852 \\
\hline 49 & 50 & 51 & 52 & 53 & 54 & 54 & 55 & 56 & 57 & 58 & 59 \\
\hline 6109 & 6225 & 6350 & 6381 & 6530 & 6715 & 6750 & 6954 & 7214 & 7277 & 7331 & 7373 \\
\hline 60 & 61 & 62 & 63 & 64 & 65 & 66 & 67 & 68 & 69 & 70 & 71 \\
\hline 7688 & 7704 & 8118 & 8312 & 8391 & 8529 & 8689 & 8785 & 8969 & 8993 & 9094 & 9203 \\
\hline 72 & 73 & 74 & 75 & 76 & 77 & 78 & 79 & 80 & 81 & 82 & \\
\hline 9363 & 9461 & 9938 & 9987 & 10440 & 11281 & 11299 & 12229 & 12300 & 12804 & 13458 & \\
\hline \multicolumn{12}{|c|}{ Operating time without failure $[\mathrm{EH}]$} \\
\hline 23 & 135 & 214 & 324 & 357 & 369 & 533 & 583 & 589 & 656 & 700 & 729 \\
\hline 743 & 819 & 924 & 928 & 944 & 1001 & 1004 & 1007 & 1187 & 1244 & 1324 & 1385 \\
\hline 1405 & 1412 & 1428 & 1442 & 1543 & 1647 & 1746 & 1872 & 1933 & 1940 & 1972 & 2119 \\
\hline 2251 & 2625 & 2646 & 2797 & 2814 & 2816 & 2905 & 3033 & 3051 & 3057 & 3084 & 3088 \\
\hline 3142 & 3213 & 3244 & 3255 & 3311 & 3317 & 3467 & 3503 & 3539 & 3541 & 3576 & 3655 \\
\hline 3719 & 3757 & 3780 & 3782 & 3983 & 4041 & 4095 & 4218 & 4320 & 4333 & 4345 & 4368 \\
\hline 4425 & 4435 & 4498 & 4511 & 4602 & 4683 & 4762 & 4789 & 4833 & 4849 & 4913 & 4946 \\
\hline 4980 & 5094 & 5300 & 5337 & 5380 & 5474 & 5523 & 5854 & 5918 & 5927 & 5928 & 5945 \\
\hline 5962 & 6007 & 6066 & 6112 & 6196 & 6247 & 6262 & 6395 & 6429 & 6497 & 6499 & 6500 \\
\hline 6600 & 6604 & 6884 & 6965 & 7060 & 7125 & 7335 & 7346 & 7435 & 7578 & 7674 & 7706 \\
\hline 7836 & 7932 & 7962 & 7988 & 8055 & 8132 & 8219 & 8413 & 8431 & 8549 & 8570 & 8625 \\
\hline 8721 & 8798 & 8901 & 9200 & 9380 & 9386 & 9444 & 9495 & 9540 & 9803 & 9956 & 10141 \\
\hline 10848 & 10904 & 11293 & 11300 & 11527 & 11781 & 12095 & 12326 & 13388 & 13427 & 13713 & 14160 \\
\hline 14212 & 14844 & 15170 & 15790 & & & & & & & & \\
\hline
\end{tabular}

\section{Results and discussion}

No dependability analysis performed on similar components from same the agriculture machine monitored for so long time as presented in this article was found in the available literature. There is nothing to compare the results with. From the point of view of the conditions in which the production processes of these branches are realized and from the point of view of the composition of PE, a completely new discipline opens up for research activities - operational dependability and optimization of renewal, which must be given due attention and help practice. Dependability indicators of selected components are in tables Tab. 312. 
Tab. 3 Weibull distribution parameters, indicators of reliability from RE535729

\begin{tabular}{|c|c|c|c|}
\hline Parameter/indicator & $a$ shape parameter & $\beta$ scale parameter & MOTTF [EH] \\
\hline reliability & 1.47 & 13600.88 & 12313.36 \\
\hline
\end{tabular}

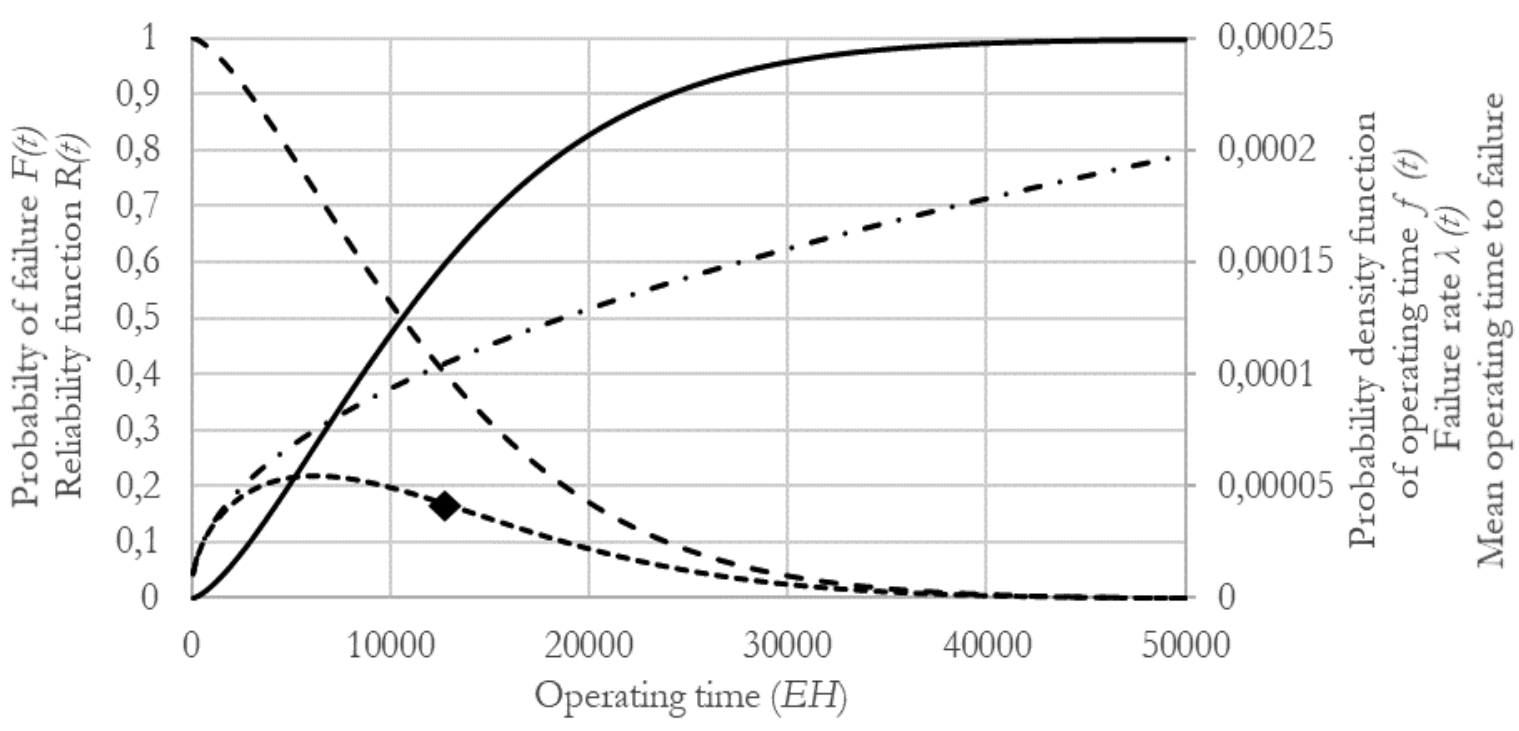

Probability of failure

- - - Realiability function

----- Probability density function of operating time

-. - Failure rate

- Mean operating time between failures

Tab. 4 Weibull distribution parameters, indicators of reliability from SE502330

\begin{tabular}{|c|c|c|c|}
\hline Parameter/indicator & $a$ shape parameter & $\beta$ scale parameter & MOTTF $[\mathrm{EH}]$ \\
\hline reliability & 1.43 & 35137.03 & 31935.82 \\
\hline
\end{tabular}

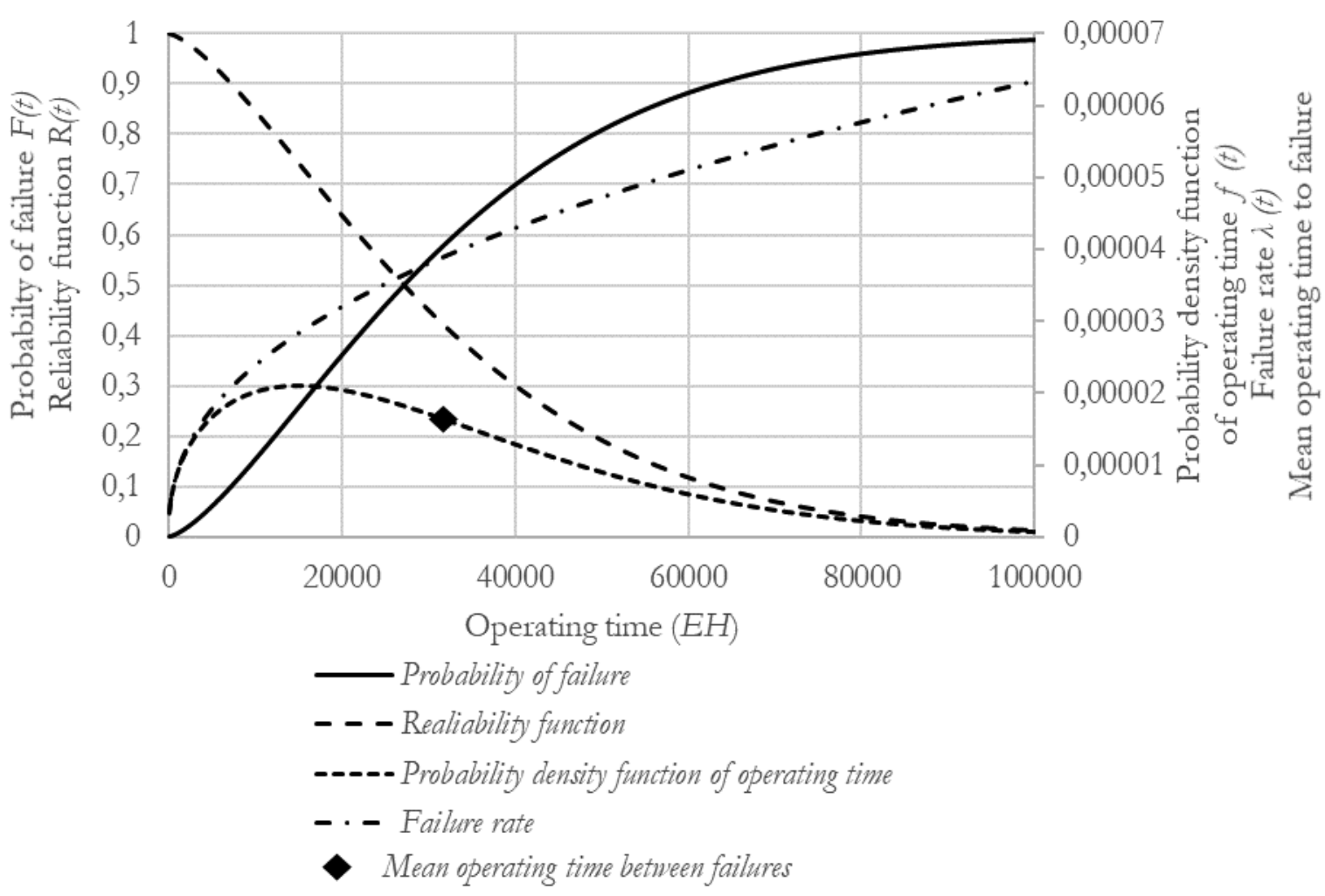


Tab. 5 Weibull distribution parameters, indicators of reliability from RE537578

\begin{tabular}{|c|c|c|c|}
\hline Parameter/indicator & $a$ shape parameter & $\beta$ scale parameter & MOTTF $[\mathrm{EH}]$ \\
\hline reliability & 3.28 & 11683.46 & 10476.91 \\
\hline
\end{tabular}
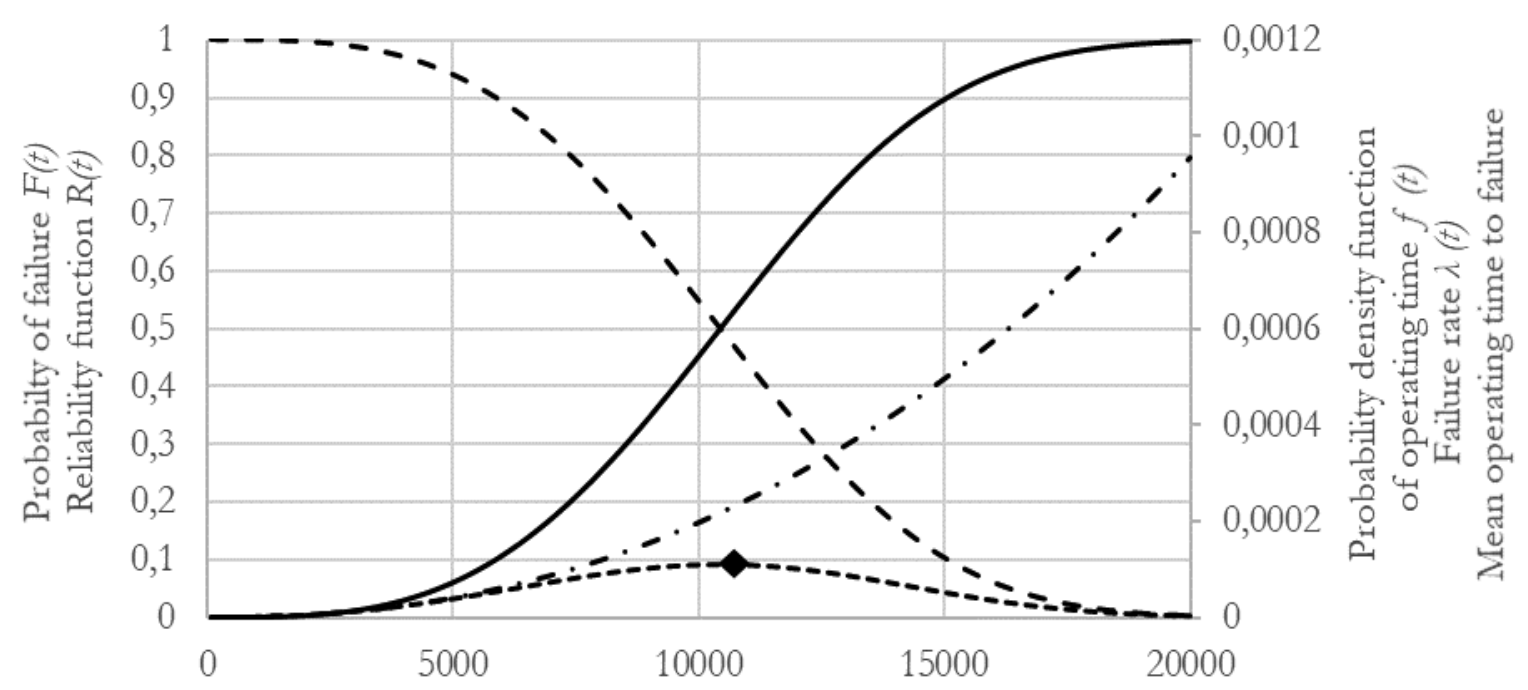

Operating time $(E H)$

- Probability of failure

- - Realiability function

----- Probability density function of operating time

-. - Failure rate

- Mean operating time between failures

Tab. 6 Weibull distribution parameters, indicators of reliability from RE43738

\begin{tabular}{|c|c|c|c|}
\hline Parameter/indicator & $a$ shape parameter & $\beta$ scale parameter & MOTTF [EH] \\
\hline reliability & 0.86 & 36663.36 & 39585.43 \\
\hline
\end{tabular}

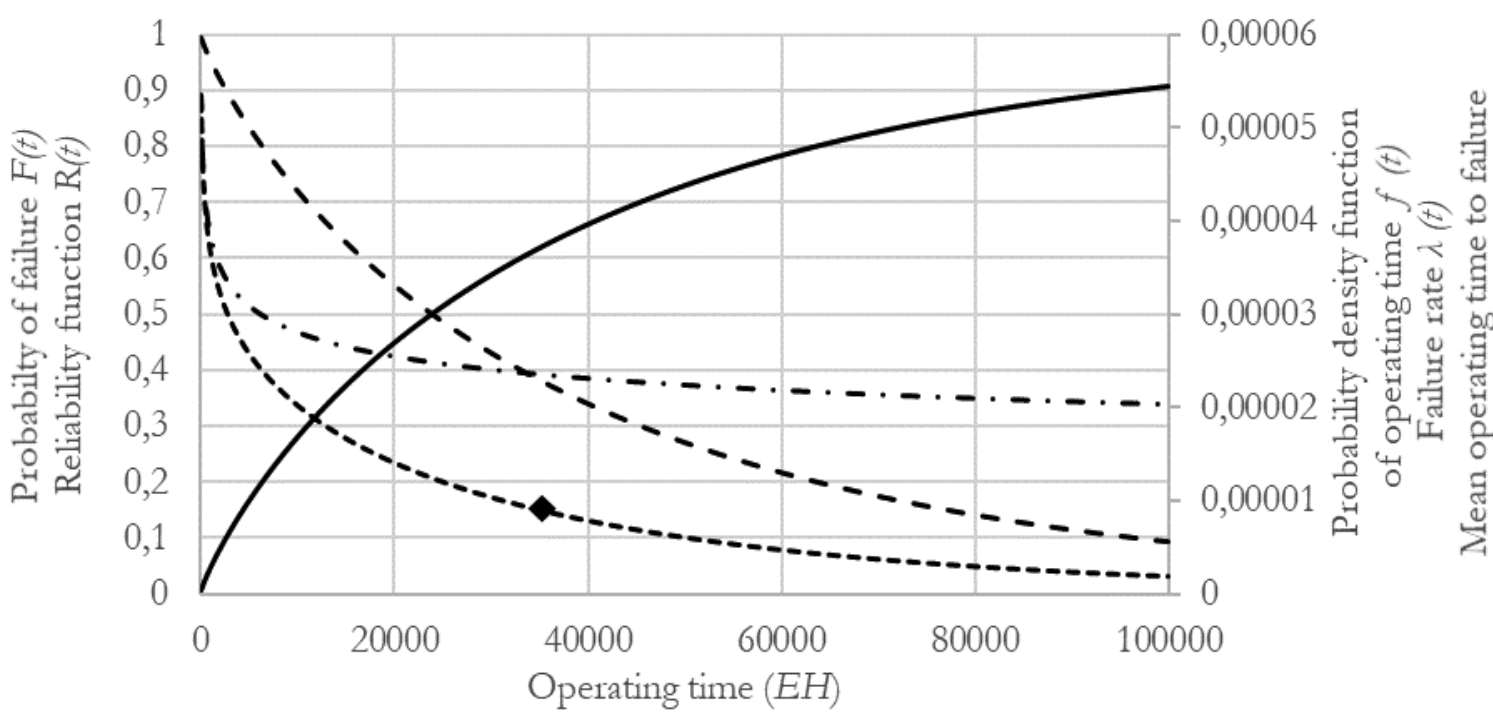

Probability of failure

- - Realiability function

----- Probability density function of operating time

-. - Failure rate

- Mean operating time between failures 
Tab. 7 Weibull distribution parameters, indicators of reliability from SE501227

\begin{tabular}{|c|c|c|c|}
\hline Parameter/indicator & $a$ shape parameter & $\beta$ scale parameter & MOTTF [EH] \\
\hline reliability & 2.86 & 14739.44 & 13136 \\
\hline
\end{tabular}

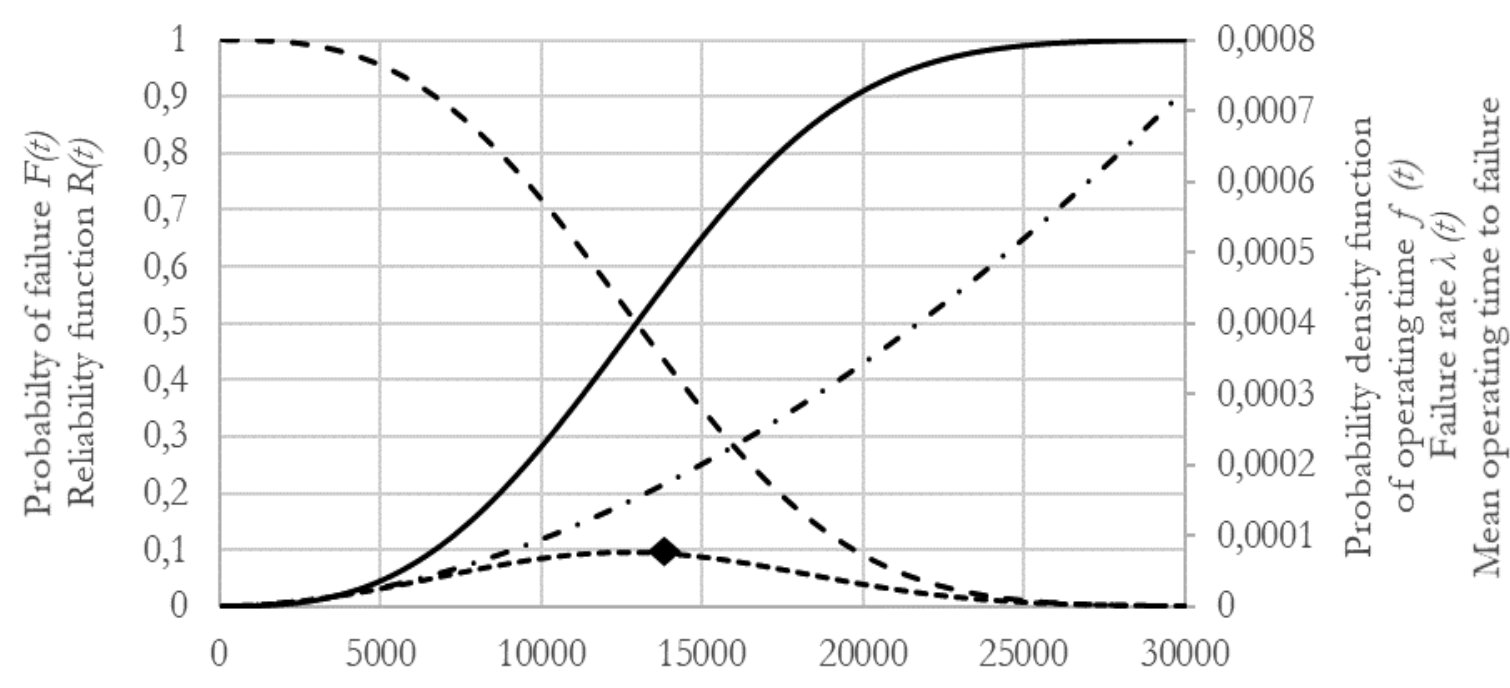

Operating time $(E H)$

- Probability of failure

- - Realiability function

----- Probability density function of operating time

- - Failure rate

Mean operating time between failures

Tab. 8 Weibull distribution parameters, indicators of reliability from AL160250

\begin{tabular}{|c|c|c|c|}
\hline Parameter/indicator & $a$ shape parameter & $\beta$ scale parameter & MOTTF [EH] \\
\hline reliability & 0.71 & 113460.41 & 141272.9235 \\
\hline
\end{tabular}

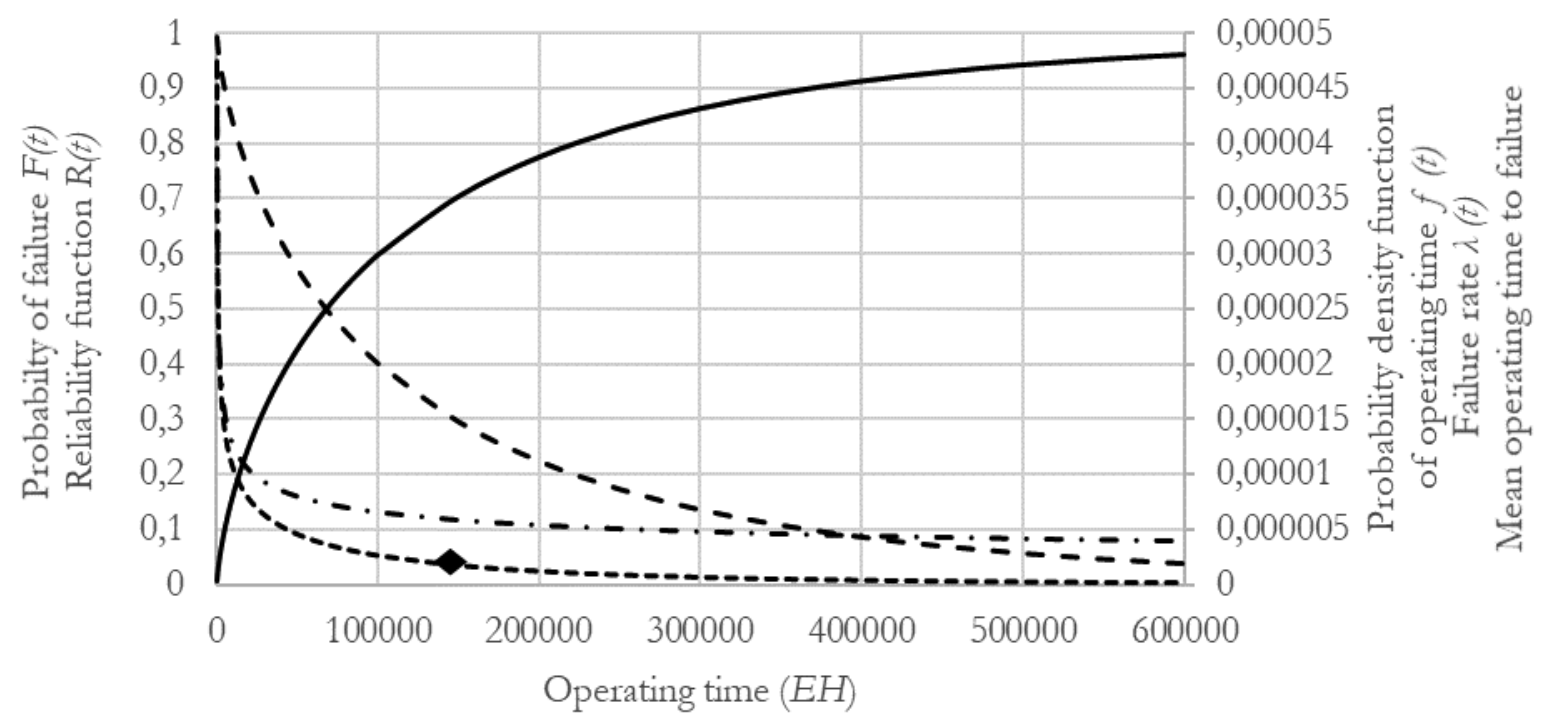

- Probability of failure

- - - Realiability function

----- Probability density function of operating time

-. - Failure rate

- Mean operating time between failures 
Tab. 9 Weibull distribution parameters, indicators of reliability from AL168483

\begin{tabular}{|c|c|c|c|}
\hline Parameter/indicator & $a$ shape parameter & $\beta$ scale parameter & MOTTF $[\mathrm{EH}]$ \\
\hline reliability & 2.58 & 22918.67 & 20351.28 \\
\hline
\end{tabular}
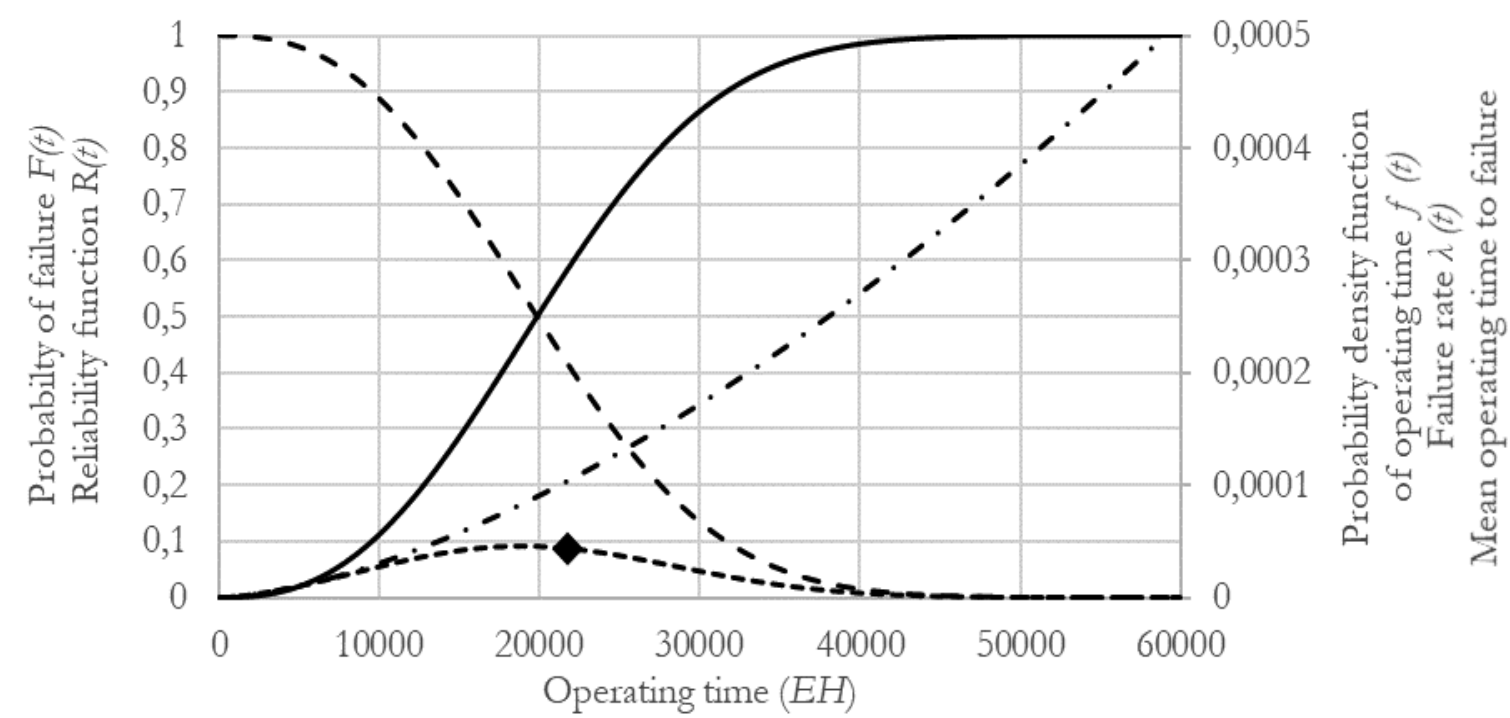

Probability of failure

- - - Realiability function

----- Probability density function of operating time

- - Failure rate

- Mean operating time between failures

Tab. 10 Weibull distribution parameters, indicators of reliability from RE543308

\begin{tabular}{|c|c|c|c|}
\hline Parameter/indicator & $a$ shape parameter & $\beta$ scale parameter & MOTTF [EH] \\
\hline reliability & 1.06 & 57134.78 & 55783.87 \\
\hline
\end{tabular}

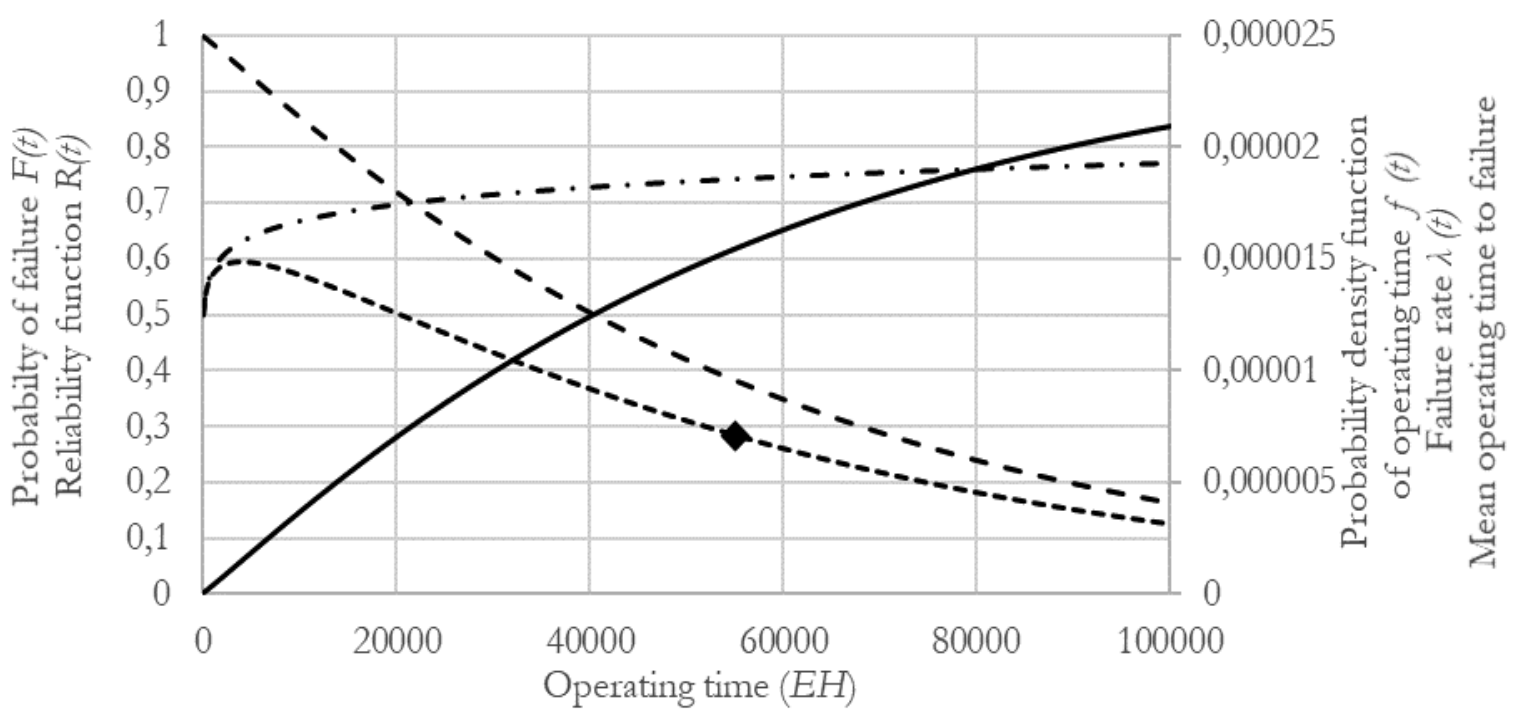

- Probability of failure

- - - Realiability function

----Probability density function of operating time

- - Failure rate

- Mean operating time between failures 
Tab. 11 Weibull distribution parameters, indicators of reliability from RE523318

\begin{tabular}{|c|c|c|c|}
\hline Parameter/indicator & $a$ shape parameter & $\beta$ scale parameter & MOTTF [EH] \\
\hline reliability & 2 & 23412.96 & 20749.07 \\
\hline
\end{tabular}
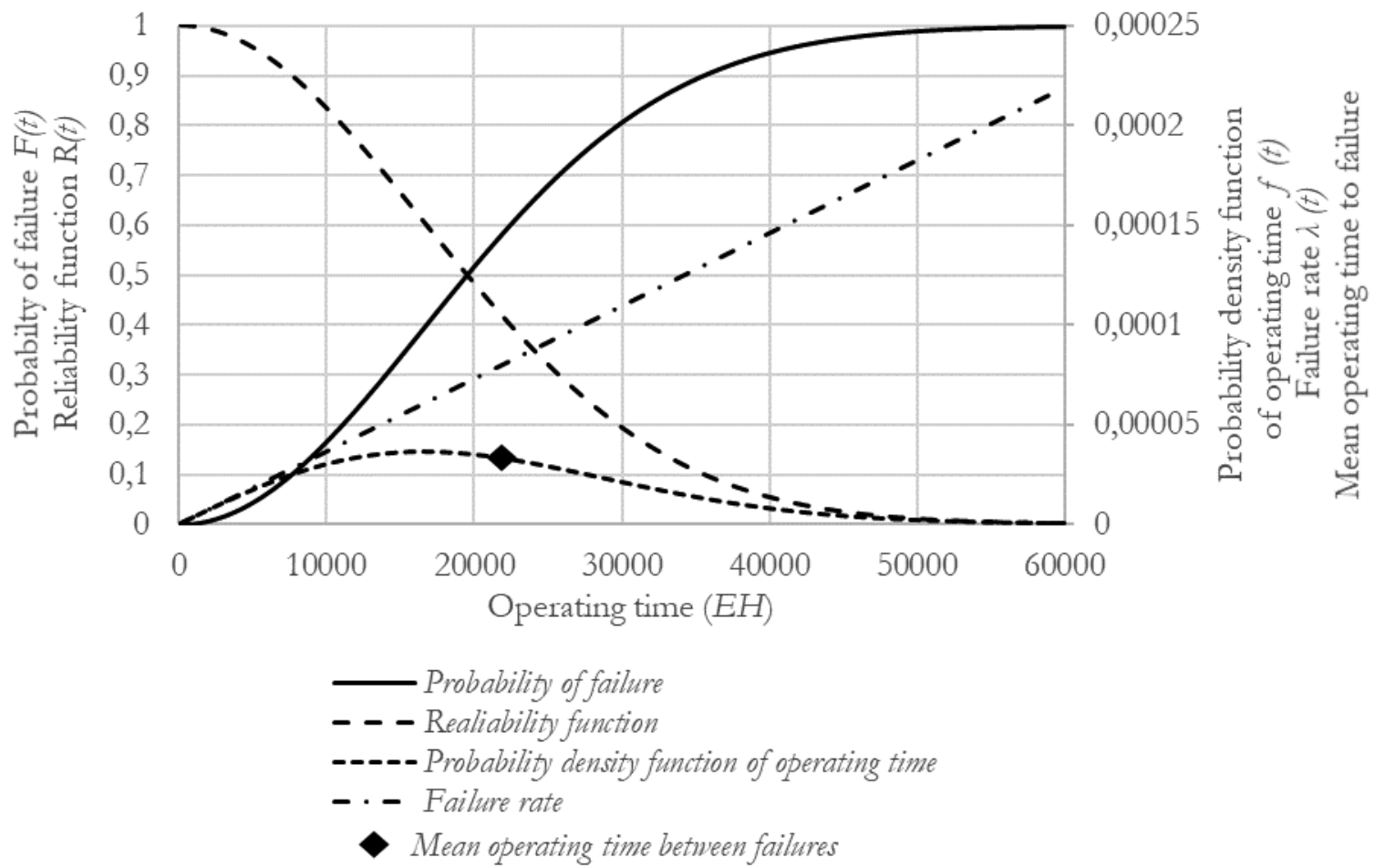

Tab. 12 Weibull distribution parameters, indicators of reliability from RE167207

\begin{tabular}{|c|c|c|c|}
\hline Parameter/indicator & $a$ shape parameter & $\beta$ scale parameter & MOTTF [EH] \\
\hline reliability & 2.03 & 21373.55 & 18936.59 \\
\hline
\end{tabular}

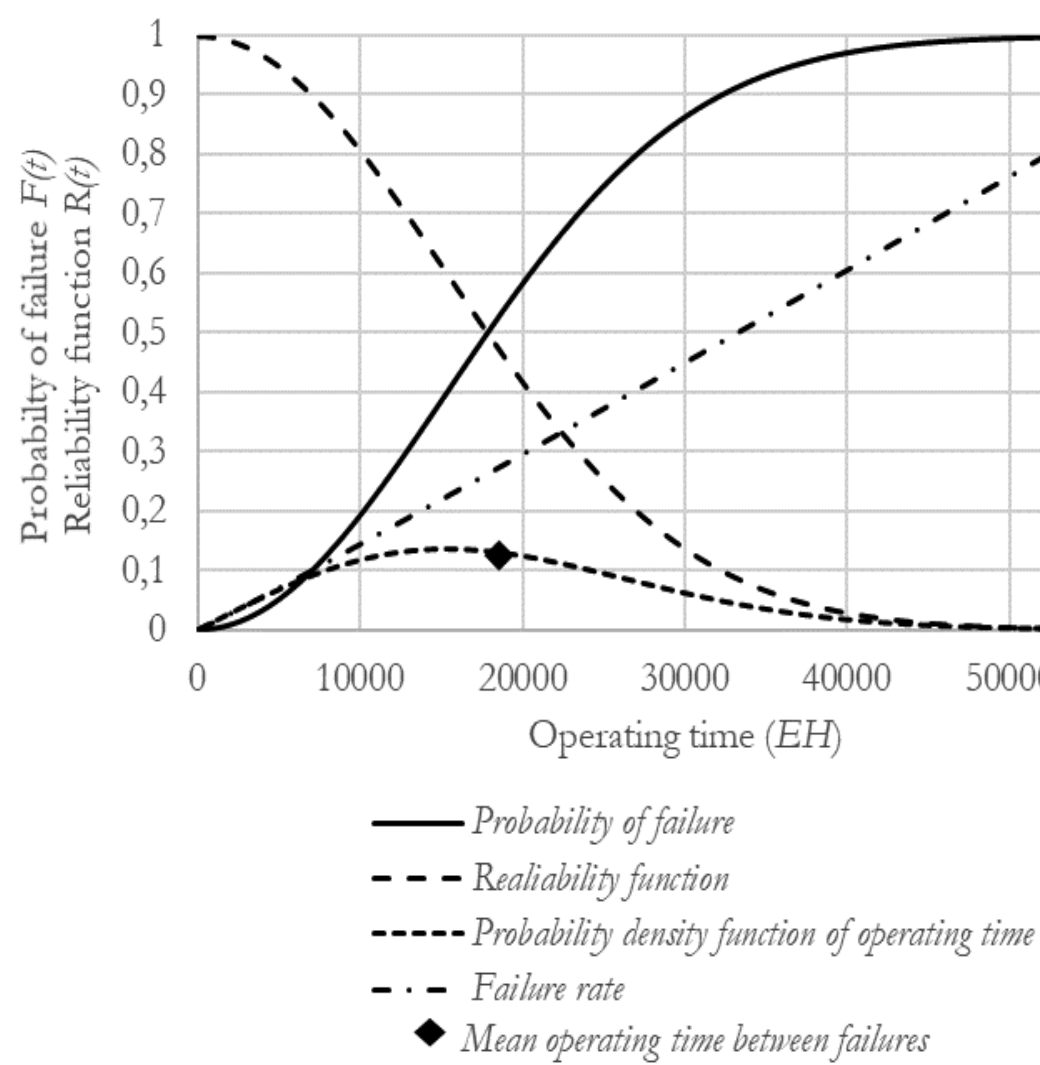

0,0003

0,00025

0,0002

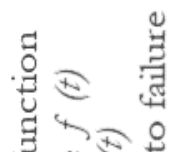

0,00015

死. 当远

0

0,0001

a

0,00005 5 o 

0

60000

Mean operating time between failures 


\section{Conclusion}

The calculated dependability indicators using equations 2-6 applied to the collected operating data of selected tractor components indicate that further research into the application of statistical methods to optimize the maintenance program of self-propelled production equipment makes senseAmong the critical components of the tractor, there are those in which the results of the failure characteristics indicate that the increase in failure intensity is not accidental in nature. However, this hypothesis needs to be confirmed by further research.

\section{References}

[1] ELMOSELHY, S., (2013). Hybrid lean-agile manufacturing system technical facet, in automotive sector. In: Journal of Manufacturing Systems, Vol. 32, No. 4, pp. 598-619.

[2] EGILMEZ, G., ERENAY, B., SÜER, G., (2014). Stochastic skill-based manpower allocation in a cellular manufacturing system. In: Journal of Manufacturing Systems, Vol. 33, No 4 , pp. $578-588$. https://doi.org/10.1016/j.jmsy.2014.05.005.

[3] LEGAT, V. (2009). Asset management - a modern way to better maintenance and use of property. In: Proceedings of the International Professional Conference Central European Maintenance Forum 2009. ČZU, Prague. ISBN 978-80-213-1999-8.

[4] LEGAT, V. (2013). Management and maintenance engineering. Professional Publishing,

[5] DOMINIK, V., VOTAVA, Z. (2016). Maintenance performance is a source of competitive advantage.

[6] LOGANATHAN, M., GANDHI, K. (2016). Maintenance cost minimization of manufacturing systems using PSO under reliability constraint. In: International Journal of System Assurance Engineering and Management, Vol. 7, No 1, pp. 47-61. doi:10.1007/s13198-0150374-2.

[7] LEGAT, V., MOSNA, F., CERVENKA, V., JURCA, V. (2002). Optimization of preventive maintenance and information system. In: Maintenance and Reliability, Vol. 4, No. 16, pp. 24-29.

[8] LEGAT, V., ZALUDOVA, A., CERVENKA, V., JURCA, V. (1996). Contribution to optimization of preventive replacement. In: Reliability Engineering and System Safety, Vol. 51,
No. 3, pp. 259-266. doi:10.1016/09518320(96)00124-X.

[9] SHERIF, Y. (1982) Optimal maintenance schedules of systems subject to stochastic failure. In: Microelectronics Reliability, Vol. 22, No. 1 pp. 15-29. doi:10.1016/00262714(82)90047-6.

[10] BARLOW, R., PROSCHAN, F. (1965). Mathematical Theory of Reliability.

[11] BURDUK, A., CHLEBUS, E. (2009). Evaluation of the risk in production systems with a parallel reliability structure. In: Maintenance and Reliability, Vol. 2, pp. 84-95.

[12] JURCA, V., HLADIK, T., ALES Z. (2008). Optimization of preventive maintenance intervals. In: Maintenance and Reliability, Vol. 3, pp. $41-44$.

[13] ALES, Z., LEGAT, V. (2016). Determination of parameters Weibull of probability density function in MS Excel. In: Weibull distribution of random variables: Materials from the 64th seminar of the expert group on reliability, pp. 17-28.

[14] GOLMAKANI, H., FATTAHIPOUR, F. (2011). Age-based inspection scheme for condition-based maintenance. In: Journal of Quality in Maintenance Engineering, Vol. 17, No. 1, pp. 93-110. doi:10.1108/13552511111116277.

[15] LI, X., JIA, Y., WANG, P., ZHAO, J. (2015). Renewable warranty policy for multiple-failuremode product considering different maintenance options. In: Maintenance and Reliability, Vol. 17, No. 4, pp. 551-560. doi:10.17531/ein.2015.4.10.

[16] ZARETALAB, A., HAGHIGHI, S., MANSOUR, S., SAJADIEH, M. (2020) An integrated stochastic model to optimize the machining condition and tool maintenance policy in the multi-pass and multi-stage machining. In: International Journal of Computer Integrated Manufacturing, Vol. 33, No. 3, pp. 211228. doi:10.1080/0951192X.2020.1718764.

[17] STENSTRÖM, C., NORRBIN, p., PARIDA, A., KUMAR, U. (2016) Preventive and corrective maintenance - cost comparison and cost-benefit analysis. In: Structure and Infrastructure Engineering; Vol. 12, No. 5, pp. 60361. doi:10.1080/15732479.2015.1032983.

[18] CSN EN 61649 (010653). (2009). Weibull analysis (In Czech).

[19] LEGAT, V., MOSNA, F., ALES, Z., JURCA, V. (2017) Preventive Maintenance Models - 
Higher Operational Reliability. In: Maintenance and Reliability; Vol. 19, No. 1, pp. 134-141.

[20] MiCHalKOVÁ, P., LEGAT, V., ALES, Z. (2018) Dependability analysis of the injection press using Weibull distribution. In: Manufacturing Technology, Vol. 18, No. 4, pp. 625629. doi:10.21062/ujep/152.2018/a/12132489/MT/18/4/625.
[21] LOULOVA, M., SUCHANEK, A., HARUSINEC, J., STRAZOVEC, P. (2018) Analysis of a railway vehicle with unevenness on wheel. In: Manufacturing Technology, Vol. 18, No. 2, pp. 266-272. doi:10.21062/ujep/89.2018/a/12132489/MT/18/2/266. 